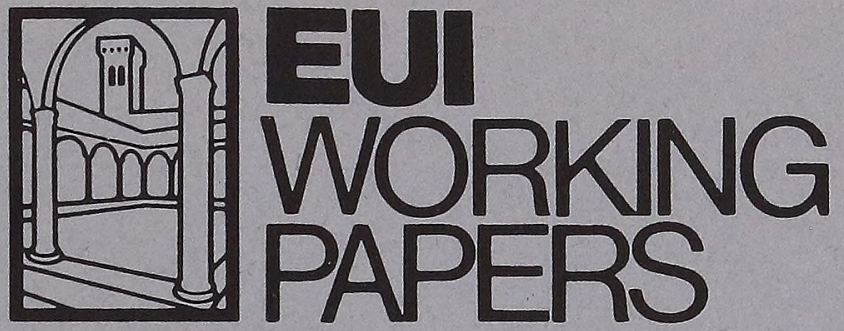

E U I WORKING PAPER No. $89 / 425$

On the Impossibility of Perfect Capital Markets

PETER J. HAMMOND 


\section{EUROPEAN UNIVERSITY INSTITUTE, FLORENCE}

DEPARTMENT OF ECONOMICS

EUI WORKING PAPER No. $89 / 425$

On the Impossibility of Perfect Capital Markets

PETER J. HAMMOND

BADIA FIESOLANA, SAN DOMENICO (FI) 
All rights reserved.

No part of this paper may be reproduced in any form without permission of the author.

() Peter J. Hammond

Printed in Italy in January 1990

European University Institute

Badia Fiesolana

- 50016 San Domenico (FI) -

Italy 


\title{
ON THE IMPOSSIBILITY OF PERFECT CAPITAL MARKETS
}

\author{
Peter J. HAMmond \\ Department of Economics, European University Institute, \\ Badia Fiesolana, 50016 S. Domenico (FI), Italy \\ and Stanford University, CA 94305-6072, U.S.A.
}

August 1987; extensively revised: January and November 1989.

\begin{abstract}
Perfect capital markets require linear budget cởnstraints, without credit rationing creating any tight borrowing constraints before the end of agents' economic lifetimes. Yet lifetime linear budget constraints are totally unenforceable. This paper considers what allocations can be enforced through monitoring in a simple two period economy when agents have private information regarding their endowments. Then default may not become apparent soon enough for any economic penalty to be an effective deterrent. Instead, borrowing constraints must be imposed to control fraud (moral hazard). Adverse selection often implies that some borrowing constraints must bind, creating inevitable capital market imperfections.
\end{abstract}

\section{ACKNOWLEDGEMENTS}

This naner is a drastically revised version of Hammond (1987b), which was originally preduced with the support of U.S. National Science Foundation Grant SES-85-20666 to the Institute for Mathematical Studies in the Social Sciences, Stanford University. It has evolved through presentations at C.O.R.E., at Western Ontario, Southern Methodist, Tulane, Stanford, Cambridge, Mannheim, Southampton, Oxford and Bonn Universities, at the Ecole Normale Supérieure in Paris, the University of California at San Diego, and to the European Meeting of the Econometric Society in Budapest. My gratitude to all the participants for their encouragement, to Frank Hahn, Mordecai Kurz, and Joe Stiglitz for extensive discussions, as well as to an anonymous referee and Ed Green for useful suggestions. 


\section{IMPERFECT CAPITAL MARKETS}

Neither a borrower nor a lender be;

For loan oft loses both itself and friend, And borrowing dulls the edge of husbandry.

- Hamlet (Act I, Scene 3, 75-77)

But where a system of borrowing and lending exists, by which I mean the granting of loans with a margin of real or personal security, a second type of risk is relevant which we may call the lender's risk. This may due either to moral hazard, i.e., voluntary default or other means of escape, possibly lawful, from the fulfilment of the obligation, or to the possible insufficiency of the margin of security, i.e., involuntary default due to the disappointment of expectation.

- Keynes (1936, p. 144)

But contracts which encourage the dishonest select adversely.

- HAHN (1988, p. 970)

A lot of money got put into people's pockets and they've rat-holed it somewhere. Some of it is in artwork, fancy homes, fancy airplanes and Rolls-Royces. Some of it went to Rolex watches, lizard shoes, hunting parties and yachts.

- The New York Times (January 10, 1989) ${ }^{1}$

1 Quoted from a statement by H. Joe Selby, former chief regulator for the Federal Home Loan Bank of Dallas. 


\section{Introduction}

\subsection{Unenforceable Budget Constraints}

The general equilibrium theory developed by Walras, Arrow, Debreu, Radner and others, and expounded in Arrow and Hahn (1971), involves linear budget constraints and market clearing prices. For intertemporal environments, this is what is required for "perfect" capital markets, in which agents are free to borrow and lend at the same market rate of interest for all loans of the same maturity, and the rates of interest adjust to match the plans of borrowers and lenders. This theory is for an economy of honourable agents, who always satisfy their intertemporal budget constraints. Agents never expose themselves deliberately to the risk of default. With perfect foresight, no default would ever occur. Without perfect foresight, of course, some agents may be unable to avoid bankruptcy ex post, as was realized by Green (1974) and Bliss (1976), amongst others. Yet in the theory of temporary equilibrium, as surveyed recently by Grandmont (1982, 1988), agents still arrange their affairs so that, according to their own expectations, they can fulfill their budget constraints with probability one. As Milne (1980) has pointed out, this is consistent with two traders making a contingent contract which each is sure that he himself can honour, and yet is sure that the other cannot! By contrast, the world is full of less honourable agents who, to the extent that they find it profitable, will knowingly incur debts which they may find themselves unable to honour ex post.

\subsection{The Need for Credit Rationing}

Jaffee and Russell (1976) showed the need for non-linear pricing of credit in a model where some borrowers would undertake investment projects leading to a risk of default on their loans, while others would arrange always to honour their budget constraint, but where the two types were indistinguishable ex ante. Later work by Stiglitz and Weiss $(1981,1983)$ demonstrates the need, in a somewhat more elaborate model, not only for non-linear pricing, but also for a ceiling on borrowing and also, in some cases, for asymmetric treatment of borrowers who are identical 
ex ante. Apart from being restricted to somewhat special economic environments, this work did not point out how what Keynes (1936, p. 144) called "moral hazard, i.e., voluntary default," affects even economies without uncertainty. Nor did it explain either why some agents would choose to repay their loans, or why others would choose to expose themselves to the risk of becoming defaulters. Without drastic non-economic penalties, some agents will gain by deliberately planning to violate their Walrasian budget constraints. There has been some recognition of this by Allen $(1981,1983)$ and by Eaton and Gersovitz (1981). Yet their work includes production, or international debt, in a way which may obscure somewhat the fact that enforcement is a problem even in the simplest of intertemporal exchange economies.

In fact the essential difficulty in having perfect capital markets turns out to be the incredibility of an intertemporal Walrasian budget constraint. This actually places no limit whatsoever upon what an agent is allowed to borrow. In a two period economy, an honourable agent will not borrow more than he anticipates being able to repay, with interest. But a dishonourable agent can borrow an arbitrarily large amount, and face the consequences of default later on. For some dishourable consumers who do not care much about the future - perhaps because they are so ill that their survival is even in doubt - no bankruptcy penalty will be able to deter them from deliberate default, so the Walrasian budget constraint fails completely to limit their borrowing.

Real economies may have few consumers with such preferences. Yet real economies do have firms whose owners enjoy limited liability, and legal restrictions are clearly needed to prevent the owners having the firm borrow indefinite amounts which are then paid out as dividends to the owners, leaving the firm bankrupt. The usual Walrasian models typically presume honourable agents who, when they die, leave estates large enough to discharge any debts. Such budget constraints are especially impossible to enforce because agents have to die before they can be declared in default. One could have all liabilities as well as assets inherited by descendants (if there are any) even if the deceased is unable to discharge his 
debts. But, with perfect capital markets, the descendants themselves can borrow to discharge the debts they have just inherited, so this is no deterrent either. To put the matter at its simplest, budget constraints can only be enforced if there is a credit ceiling or borrowing constraint at some date in the future, otherwise debts of any size can be rolled over and allowed to grow indefinitely. Such credit ceilings may appear to create imperfections in the capital market:

\subsection{Feasible Allocation Mechanisms}

Credit ceilings may not, however, make capital markets imperfect by themselves. Suppose that we were in an Arrow-Debreu economy in which any information that becomes available to one agent becomes available to all simultaneously. Thus all information would be public, and there would be a publicly known event tree (cf. Debreu, 1959). Then all agents would know what contingent contracts other agents could honour. In other words, at each event of the publicly known tree, it would be possible to limit each agent's total net short sales of Arrow contingent securities and/or Debreu contingent commodity contracts to what that agent was known to be able to repay for sure after that event has occurred. This form of credit rationing is mentioned by Foley and Hellwig (1975). It makes the Arrow-Debreu budget constraint enforceable by replacing it with an entire sequence of short selling constraints preventing the agent from ever becoming excessively indebted in any possible event. Yet any allocation which is achievable in Arrow-Debreu complete markets is still achievable with these "perfect" shortselling constraints. These constraints only prevent default - they do not prevent any agent from making any short sale which can actually be honoured for sure. Equilibrium allocations with such perfect constraints are identical to those in perfect capital markets, and no loss of efficency or welfare will result.

The above discussion makes it clear then that credit rationing only creates capital market imperfections when we move outside the standard Arrow-Debreu framework of a publicly known event tree. Even so, there are some forms of asymmetric information that still fail to create problems for Walras-Arrow-Debreu perfect capital market allocations. For example, if there is a continuum economy with 
private information regarding only agents' preferences, then the results of Hammond (1979) for static continuum economies are easily integrated with those of Gale $(1980,1982)$ and Harris and Townsend (1981) for resource allocation mechanisms in sequence economies. The point is that private information concerning preferences does not destroy the publicly known limits on what each agent in each event is able to borrow without any risk of later default.

Although the literature on incentive compatibility concentrates on the special case when only preferences are private information, this is, of course, very special. Real economic systems must deal with private information concerning labour skills (cf. Mirrlees, 1971; Dasgupta and Hammond, 1980; Maskin, 1980) or endowments (Postlewaite, 1979; Hurwicz, Maskin and Postlewaite, 1979; Maskin, 1980; Postlewaite, 1985). This last group of papers, however, assumes that individuals are allowed only to understate their true skill or to understate or perhaps even destroy their endowments. This is the kind of manipulation to which Walrasian equilibrium allocation mechanisms are often vulnerable. As Hurwicz, Maskin and Postlewaite in particular have pointed out, if individuals can overstate their true endowments instead, and if their consumption sets are bounded below, then there will be a problem in ensuring that an allocation mechanism actually produces feasible outcomes.

In addition, Green (1987) has considered an infinite horizon economy with a continuum of agents in which each individual's endowment stream is private information. But there is a single commodity and utility is both additively separable and negative exponential. The possibility of an infeasible net trade vector never arises, because agents are modelled as being always able to repay any arbitrarily large sum which they may have borrowed in the past, even if this requires negative consumption in some periods. Of course, in Green's model it might well take a very long run of unluckily low endowments before a debtor was forced to suffer negative consumption. Nevertheless, the feasibility issue with which I shall specifically be concerned is not addressed.

My own past work (Hammond, 1979, 1987a) and that of Gale $(1980,1982)$ has 
concentrated on allocations of net trade rather than consumption vectors. This implicitly allows agents' endowments and feasible sets (consumption sets, together with any domestic production possibilities) to be private information. It does not really deal with the feasibility issue satisfactorily, however, because it assumes explicitly that agents in any game form will never choose strategies which could result in net trade vectors that are infeasible for them.

If the economy only lasts for a single period, this last assumption can often be justified by suitable monitoring of defaulters. For if an agent in a game form plays a strategy which would result in an infeasible net trade vector, presumably this fact is discovered before the allocation has been determined irreversibly. After all, even if consumption demand falls below subsistence, that is typically still feasible for an agent who is not supplying anything, as discussed in Coles and Hammond (1986): So an infeasible net trade vector only arises, one may assume, when a "defaulting" agent fails to supply something that has been promised. Typically this will be detected, if only because some agent who was expecting to receive at least a part of this supply will be disappointed and can be relied upon to complain. Then, in a single period economy, it is not too late to change the allocation by requiring the defaulting agent to amend his net trade vector to one that really is feasible. Indeed, it may be possible to monitor any defaulter's endowments, if necessary, and to confiscate enough of them to deter any such defaults.

In a sequence economy, however, the situation can be quite different. Suppose for simplicity that the economy lasts for just two periods. Then a consumer may be able to play the game form in a way which appears in the first period to ensure feasibility, but involves commitments which cannot possibly be honoured in the second period. More concretely, an agent may be able to consume excessively in the first period by acting in the economic system as would someone whose endowments were much larger, in effect borrowing more than can ever be repaid. If the agent has been careful, this inability to repay will not manifest itself until the second period. By then it may be too late to make appropriate rearrangements in order to enforce the intertemporal allocation mechanism which is incentive compatible 
in the usual sense. It may even be too late to punish the defaulter severely enough to deter such default - the defaulter may have disappeared without trace, or even died. Excessive consumption of this kind, of course, is precisely what fraudulent borrowers achieve in actual economies. In real economies defaulters have the additional advantage of being able to seek the protection of bankruptcy laws. Such deliberate default may be criminally fraudulent, but it does occur.

In any case, potential fraud of this kind introduces a form of moral hazard to add to the obvious problems of adverse selection arising from private information about future endowments. The consequences of default really need to be specified within the game form, and the question of whether there can ever be economic penalties strong enough to deter all default carefully investigated within such a framework. ${ }^{2}$

\subsection{Additional Incentive Constraints}

So Section 2 below considers allocation mechanisms with monitoring in order to take this additional moral hazard into account. This is done with a simple two period economy having just one consumption good. In the first period each agent has private information which tells him exactly what his second period endowment will be. Only in the second period does default become apparent, however, and only in the second period is it possible to use monitoring in order to acquire public information about the second period endowment. By the time the second period arrives, it is too late to reduce a defaulting borrower to autarky because the benefit from the loan taken out in the first period can no longer be taken away. Thus in sequence economies it becomes necessary to consider additional incentive or "individual feasibility" constraints, beyond those already considered in Hammond (1979, 1987a), Gale (1980, 1982), Harris and Townsend (1981), Prescott and Townsend (1984a, b), Townsend (1988), etc. And to introduce credit rationing in a way which may well prevent attainment of an allocation which

2 A similar point has already been made by Shubik $(1973,1974)$ in the context of a very specific trading game, but only with a finite number of players. Shubik and Wilson (1977), as well as Dubey and Shubik (1979), do consider continuum economies, but they also introduce non-economic penalties for bankruptcy. 
"perfect" capital markets would produce, if only Arrow-Debreu budget constraints could somehow be enforced.

This may appear to contradict the results of Harris and Townsend (1981) on incentive constraints in sequence economies. They were careful to consider mechanisms as extensive form games and to demonstrate the revelation principle for "perfect Bayesian equilibrium," closely related to Kreps and Wilson's (1982) concept of "sequential equilibrium." They proved that a sequential allocation mechanism is implementable in perfect Bayesian equilibrium strategies if and only if there is an equivalent direct mechanism in which each individual commits himself to a single strategy of direct revelation, and in which to do so truthfully is a Bayesian equilibrium (Theorems 1 and 2, pp. 46-7).

By contrast, in Section 3 below the equivalent direct mechanism will be required to depend not merely on the first period announcement of the second period endowment, as would be the case for the kind of equivalent direct mechanism which Harris and Townsend construct. In addition, the need for monitoring implies that in the second period the equivalent direct mechanism must also depend on what the second period endowment actually turns out to be, which will be different if a false announcement has been made in the first period. It is as though agents were allowed to revise their earlier announcements and to claim that they had previously misstated their true type. In Harris and Townsend's framework, this kind of claim is equivalent to no more than a different and inconsistent deceptive strategy in the original (indirect) game form, and never benefits the deceiver in equilibrium. But their framework incorporates the assumptions of a known common consumption possibility set (p. 40) and a known set of allocations which are "achievable" or feasible for each coalition of agents (p. 41). Since a coalition of size one can presumably achieve only its initial endowment, or some private production possibility set, this specifically rules out the crucial assumption that a.gents are privately informed of their own endowments. Indeed, in Harris and Townsend's framework, private information never affects what is feasible. Accordingly, it should not be surprising if their results need some modification in sequence economies for which 
there is private information regarding endowments, consumption sets, or private production possibility sets. When one constructs an equivalent direct mechanism in such a sequence economy, one cannot afford to ignore any non-null set of agents who claim that they previously misstated their types and now cannot supply what they are supposed to - some form of monitoring and modification of their net trade vectors seems inevitable, if the allocation mechanism really is to be implementable in dominant strategies. That is why both the announced and the true endowments feature in the equivalent direct mechanism of Section 3. One can expect more complicated equivalent direct mechanisms to emerge when there are many periods in which monitoring may be triggered. And corresponding additional incentive constraints.

\subsection{Outline}

Section 2 will set out the basic assumptions of a continuum economy lasting for two periods with one good each period. It also describes the basic framework of extensive game forms in which endowment monitoring is used to ensure individual physical feasibility. Thereafter Section 3 discusses implementation in dominant strategies as well as the incentive and individual feasibility constraints which this requires. It also describes the problem of finding incentive constrained Pareto efficient allocation mechanisms. Then Section 4 explores the conditions under which an allocation mechanism can be implemented without any monitoring occurring in equilibrium. Section 5 is concerned with the decentralization of incentive compatible mechanisms, and particularly with the need for credit rationing in some economic environments. It also presents a general demand revelation game form which produces an incentive compatible allocation mechanism for the class of economic environments described in Section 2, and then illustrates it with an example. Conclusions are set out in Section 6. 


\section{Two Period Extensive Game Forms with Endowment Monitoring}

\subsection{A Continuum Economy}

Consider a continuum economy with a non-atomic measure space of agents $(N, \mathcal{N}, \nu)$ - in fact, one could assume that $N=[0,1] \subset \Re$, that $\mathcal{N}$ is the usual Borel $\sigma$-algebra, and that $\nu$ is the usual Lebesgue measure. For simplicity, suppose that all agents $i \in N$ have the same known utility function $u: \Re_{+}^{2} \mapsto \Re$ which is continuous and strictly increasing on the known common consumption set $\Re_{+}^{2}$. To keep the model simple, suppose also that all agents have the same known endowment of 1 in the first period, but that their different second period endowments $e \in \Re_{+}$remain as private information in the first period, and can only be discovered through monitoring in the second period. Assume too that there is a set $E \subset \Re_{+}$of possible second period endowments. Note that no trade is always possible for each consumer, even if it does not necessarily guarantee survival.

\subsection{Random Endowments}

Suppose that the allocation mechanism in this economy is given by an extensive game form with the following sequence of events. At the first stage of the game, nature determines at random the endowment vector $e_{i}$ of each agent $i \in N$. The function $e(\cdot): N \mapsto \Re_{+}$need not be measurable, but it will be assumed that there is a well-defined joint distribution $\lambda \in \Delta(N \times E)$ of agents' names and endowments given by

$$
\lambda(K)=\nu\left(\left\{i \in N \mid\left(i, e_{i}\right) \in K\right\}\right)
$$

for every Borel set $K \subset N \times E$. This will be true, for instance, if different individuals' endoments are independently and identically distributed, even though a continuum of random variables almost never produces a measurable function (cf. Gale 1979, Feldman and Gilles 1985, and Judd 1985). It should be noted after all that measurability of the function $e(\cdot)$ is a sufficient but unnecessary condition for the measure $\lambda$ to exist. Obviously, $\lambda$ induces the marginal distribution $\nu$ on $N$. 
Agents $i \in N$ are supposed to be informed only of their own endowments $e_{i}$, and to remain uninformed about the endowments of others, or even the distribution $\lambda$.

\subsection{Strategies}

At the second stage of the game form, each agent has the same set $A$ of possible strategies $a$. These can be interpreted as bargaining strategies, offers to borrow and lend, announcements of credit demand functions, or whatever. All agents $i \in N$ choose their strategy functions $a_{i}: E \mapsto A$ specifying how their respective actions in the economic system depend on their endowments, which represent the differences in what they know. There is no reason to presume that the resulting function $a(\cdot): N \times E \mapsto A$ is measurable, but it is assumed that $a(\cdot)$ induces a well defined joint distribution $\sigma \in \Delta(N \times E \times A)$ on the set of agents' names, endowments and strategies which is given by

$$
\sigma(K)=\lambda\left(\left\{(i, e) \in N \times E \mid\left(i, e, a_{i}(e)\right) \in K\right\}\right)=\nu\left(\left\{i \in N \mid\left(i, e_{i}, a_{i}\left(e_{i}\right)\right) \in K\right\}\right)
$$

for every Borel set $K \subset N \times E \times A$. This distribution has appropriate marginals $\lambda$ on $N \times E$ and so $\nu$ on $N$, of course. Also, let $\alpha(\sigma) \in \Delta(N \times A)$ denote the resulting marginal joint distribution of agents' strategies and names in the game form, which is given by

$$
\alpha(\sigma)(K)=\lambda\left(\left\{(i, e) \in N \times E \mid\left(i, a_{i}(e)\right) \in K\right\}\right)=\nu\left(\left\{i \in N \mid\left(i, a_{i}\left(e_{i}\right)\right) \in K\right\}\right)
$$

for every Borel set $K \subset N \times A$. It will be assumed that this distribution is observable by all individuals in the economy, including those responsible for arranging net trades and any monitoring activities which are undertaken at later stages of the game form. 


\subsection{The Provisional Allocation Mechanism}

Suppose now that, at the third stage of the game form, and still in the first period of the sequence economy's two periods, a provisional allocation of net trades

$$
\xi_{i}^{0}(a, \alpha): N \times A \times \Delta(N \times A) \mapsto \Re^{2}
$$

is determined for each agent $i$, as a function of $i$ 's strategy in the game form, as well as the entire distribution of strategies played by all the other agents. Notice that $\xi_{i}^{0}(\cdot)$ does not depend upon $i$ 's endowment $e_{i}$ except insofar as it helps to determine $i$ 's strategy in the game form. So the allocation mechanism is not using private information. It is presumed that the first period part of this provisional mechanism, $\xi_{i 1}^{0}(a, \alpha)$, is put into immediate effect during this third stage, and that this is always possible because $\xi_{i 1}^{0}(a, \alpha)+1 \geq 0$ for all $i \in N, a \in A$, and $\alpha \in \Delta(N \times A)$. It is presumed in addition that the second part of this provisional mechanism, $\xi_{i 2}^{0}(a, \alpha)$, will also come into effect unless there is some non-null set of agents who default in the second period by failing to repay what the provisional mechanism prescribes.

\subsection{Endowment Monitoring}

In the second period, the game form goes on to fourth and further stages. First it is assumed that agents are given the opportunity to make payments to each other voluntarily, in an effort to settle their debts if they want to. If these voluntary payments do in fact settle (almost) all debts, so that (almost) all agents $i \in N$ have their appropriate net expenditures $\xi_{i 2}^{0}(a, \alpha)$, then the game stops and the provisional allocation becomes the actual one. Otherwise creditors pursue defaulting debtors and set in motion processes of monitoring and debt collection, as is the standard practice in bankruptcy proceedings. It is therefore natural to suppose that monitoring signals are affected by true endowments - indeed, in the extreme case of perfect monitoring, an agent's true second period endowment will be discovered. Thus the monitoring signal $m_{i} \in M$ for each monitored a.gent $i \in N$ is supposed to be a deterministic but possibly imperfect indicator of the 
true endowment $e_{i}$ - obviously, randomness could be introduced into a more complicated model.

In fact, it will ease notation to suppose that all agents are monitored, but that for some of them the monitoring only produces a "null signal" $m_{0}$ which can be interpreted as meaning that no real monitoring has taken place. It is therefore assumed that there is a monitoring function

$$
m_{i}(e, a, \sigma): N \times E \times A \times \Delta(N \times E \times A) \mapsto M
$$

The range of this is function is taken to be the fixed set $M$ of possible monitoring signals, which has the null signal $m_{0}$ as one of its members. For technical reasaons it will be necessary to assume that $M$ can be given a topology and so also a Borel $\sigma$-algebra of measurable sets. Of course, this is hardly a serious restriction.

Note that the monitoring signal is allowed to depend on the entire joint distribution $\sigma \in \Delta(N \times E \times A)$ of agents' names, endowments, and strategies, rather than just on the marginal distribution $\alpha(\sigma) \in \Delta(N \times A)$ of names and strategies. This is because, as discussed below, several rounds of monitoring will often be needed, with monitoring decisons at later stages depending on the results of previous monitoring.

Given the joint distribution $\sigma \in \Delta(N \times E \times A)$, this monitoring function induces a joint distribution $\mu(\sigma) \in \Delta(N \times A \times M)$ which is given by

$$
\mu(\sigma)(K):=\sigma\left(\left\{(i, e, a) \in N \times E \times A \mid\left(i, a, m_{i}(e, a, \sigma) \in K\right\}\right)\right.
$$

for every measurable subset $K \subset N \times A \times M$. It is this distribution which summarizes whatever information about individuals' endowments is available to the economic system, and how those endowments are correlated with their behaviour in that system. Let $\alpha(\mu) \in \Delta(N \times A)$ denote the corresponding marginal distribution on just names and strategies.

Notice how it can only. be true that $m_{i}(e, a, \sigma)=m_{0}$ for almost all $i \in N$ when $\xi_{i 2}^{0}(a, \alpha(\sigma))+e \geq 0$ for almost all $i \in N$. Otherwise a non-null set of agents are bound to default in the second period when the economic system tries to 
implement the provisional allocation by calling upon them to repay their debts in full. If these defaulting agents were not monitored and punished in some way, then no borrower would ever repay his debts, and the credit allocation mechanism would collapse to autarky. So non-trivial monitoring of defaulters is usually an essential part of any well functioning credit allocation system. In addition, if there is a non-null set of agents for whom $\xi_{i 2}^{0}(a, \alpha)+e<0$, their unavoidable default and the consequent changes to the allocation mechanism may trigger defaults by other agents - a familiar problem in real economies when significant numbers of agents are in financial difficulties. That is why one cannot just assume that, for each separate $i \in N, \xi_{i 2}^{0}(a, \alpha(\sigma))+e \geq 0$ implies $m_{i}(e, a, \sigma)=m_{0}$. For the same reason, several rounds of monitoring may actually be necessary, and the ultimate monitoring signal $m_{i}(e, a, \sigma)$ may not just depend on $\alpha(\sigma) \in \Delta(N \times A)$.

\subsection{The Final Second Period Allocation Mechanism}

Here, however, I shall consider only the final outcome after as many rounds as necessary of monitoring and recontracting have been carried out in order to ensure feasibility. So, in the very last stage of the game form, there will be a final second period allocation function

$$
\xi_{i 2}^{M}(a, m, \mu): N \times A \times M \times \Delta(N \times A \times M) \mapsto \Re .
$$

There is also an associated direct second period allocation function $\xi_{i 2}(a, e, \sigma)$, whose second argument is the individual's true endowment $e$ rather than the monitoring signal $m$ which was generated by $e$, and whose third argument is the joint distribution $\sigma$ in the population of combinations $(i, e, a)$. This function $\xi_{i 2}: N \times A \times E \times \Delta(N \times E \times A) \mapsto \Re$ is given by the composition

$$
\xi_{i 2}(a, e, \sigma) \equiv \xi_{i 2}^{M}\left(a, m_{i}(e, a, \sigma), \mu(\sigma)\right)
$$

of the above allocation and monitoring functions. 


\subsection{Ensuring Physical Feasibility}

Since the whole purpose of monitoring is to ensure physical feasibility, it will be assumed that, for all $(i, a, m, \sigma) \in N \times A \times M \times \Delta(N \times E \times A)$, the individual feasibility constraint

$$
\xi_{i 2}^{M}(a, m, \mu(\sigma))+e \geq 0
$$

is satisfied whenever $m=m_{i}(e, a, \sigma)$. Equivalently, after using (8), this requirement can be expressed more concisely as

$$
\xi_{i 2}(a, e, \sigma)+e \geq 0
$$

Note in particular how (10) implies that agents are not monitored only if their second period allocation without monitoring is indeed feasible. Equivalently, for agents whose second period allocation would be individually infeasible in the absence of monitoring, the inevitable default that follows must trigger active monitoring, and lead to an adjustment of the allocation to something that is feasible given the true endowment $\epsilon$. The assumption (10) guarantees that a feasible allocation always results, even when individual consumers use disequilibrium strategies. I would argue that this is an unavoidable necessary condition for an economic system to function, and that it will always be satisfied somehow. Remember, after all, that I do not assume that feasibility entails survival.

To illustrate how (10) is actually quite plausible, consider what happens when $M=\Re_{+}$and

$$
\begin{aligned}
m_{i}(e, a, \sigma) & = \begin{cases}e & \text { if } \xi_{i 2}^{M}\left(a, m_{0}, \mu(\sigma)\right)+e<0 ; \\
m_{0} & \text { if } \xi_{i 2}^{M}\left(a, m_{0}, \mu(\sigma)\right)+e \geq 0 ;\end{cases} \\
\xi_{i 2}^{M}(a, m, \mu(\sigma)) & =-m \Longleftrightarrow m \neq m_{0} .
\end{aligned}
$$

This means that agents are monitored if and only if they would have to default otherwise, and that any agent who is actively monitored because of default has all his endowment monitored and then confiscated so that consumption is forced down to zero in the second period. Because of our assumption that the consumption set is $\Re_{+}^{2}$, this guarantees individual feasibility. It will also deter default provided that 
the null monitoring consumption stream $\left(\xi_{i 1}^{0}\left(a^{*}, \alpha(\sigma)\right)+1, \xi_{i 2}^{M}\left(a^{*}, m_{0}, \mu(\sigma)\right)+e\right)$ for the best strategy $a^{*}$ is always at least weakly preferred to $\left(\xi_{i 1}^{0}(a, \alpha(\sigma))+1,0\right)$ for every alternative strategy $a \in A$. Obviously punishing defaulters by reducing their consumption to zero in the second period is rather drastic, especially as there is no guarantee that the individual defaulter can then even survive. But it does serve to show how individual feasibility might be guaranteed even out of equilibrium.

\subsection{Resource Balance}

Physical feasibility also requires aggregate resource balance constraints to be satisfied. In the second period, such constraints should reflect the resource costs of the monitoring that is required in order to bring about the specified monitoring function. Thus a reasonable formulation of such constraints is

$$
\begin{gathered}
\int_{N \times A} \xi_{i 1}^{0}(a, \alpha) \alpha(d i \times d a) \leq y_{1} ; \\
\int_{N \times A \times M} \xi_{i 2}^{M}(a, m, \mu) \mu(d i \times d a \times d m) \leq y_{2}\left(y_{1}, \mu\right)
\end{gathered}
$$

for every joint distribution $\mu \in \Delta(N \times A \times M)$ with marginal $\alpha \in \Delta(N \times A)$. Here $y_{1}$ represents the mean level in the population of net expenditure (or excess of expenditure over saving) during the first period; then $y_{2}\left(y_{1}, \mu\right)$ is an upper bound on the mean second period net expenditure levels which are physically feasible. It reflects the non-monitoring production possibilities of the economy. The dependence of $y_{2}$ on $\mu$, however, is a general formulation recognizing that producing monitoring signals according to the function $m_{i}(e, a, \alpha)$ costs real resources which are diverted from meeting the resource balance constraints in the non-monitoring sector of the economy. Note that the costs of monitoring an agent's endowments are always observable to the person doing the monitoring and so incurring the costs. For this reason they can be treated as part of the monitoring signal $m$, with a value of zero when $m=m_{0}$, the null signal.

Aggregate feasibility constraints like (12) play no role, however, in determining the incentive constraints which are our primary concern here. Thus they will 
largely be ignored except when constrained Pareto efficient allocation mechanisms are discussed in Section 3.4 below.

That completes the basic description of the multi-stage extensive game form for determining net trades in the simple two period sequence economy. Although its formulation may appear rather special at first sight, in fact it is hard to imagine any really different formulation of an economic system that both allows trades to be consummated without any monitoring when all individuals are indeed honouring their obligations, and also provides for the monitoring which is needed when there are defaulters.

\section{Implementation in Dominant Strategies}

\subsection{Dominant Strategies}

Suppose that each individual $i \in N$ in this game form has a dominant strategy function $a_{i}^{*}(e): E \mapsto A$ at the second stage which depends upon $i$ 's own endowment $e$, but not on the distribution $\alpha$ of strategies chosen by other individuals. Thus

$$
\begin{aligned}
a_{i}^{*}(e) & \in \arg \max _{a}\left\{u\left(\xi_{i 1}^{0}(a, \alpha(\sigma))+1, \xi_{i 2}^{M}\left(a, m_{i}(a, e, \sigma), \mu(\sigma)\right)+e\right) \mid a \in A\right\} \\
& =\arg \max _{a}\left\{u\left(\xi_{i 1}^{0}(a, \alpha(\sigma))+1, \xi_{i 2}(a, e, \sigma)+e\right) \mid a \in A\right\}
\end{aligned}
$$

which means that $a_{i}^{*}(e)$ is always a best response to any joint frequency distribution $\sigma \in \Delta(N \times E \times A)$ generated by the other agents' choices of strategies. Notice that there is no need to incorporate any feasibility constraint explicitly in the maximization problem (13) because of the earlier assumption (9) which implies (10). It will be assumed finally that, for each distribution $\lambda \in \Delta(N \times E)$ of names and endowments, the dominant strategy function $a_{i}^{*}(\cdot): N \times E \rightarrow A$ induces a well defined joint distribution

$$
\sigma^{*}(\lambda)(K):=\lambda\left(\left\{(i, e) \in N \times E \mid\left(i, e, a_{i}^{*}(e)\right) \in K\right\}\right) \in \Delta(N \times E \times A)
$$

for every measurable subset $K \subset N \times E \times A$, whose corresponding marginal distribution is given by

$$
\alpha^{*}(\lambda)(K):=\lambda\left(\left\{(i, e) \in N \times E \mid\left(i, a_{i}^{*}(e)\right) \in \Pi\right\}\right) \in \Delta(N \times A)
$$


for every measurable subset $K \subset N \times A$. In addition, the monitoring functions $m_{i}(e, a, \alpha)$ then determine the joint distribution in $\Delta(N \times A \times M)$ given by

$$
\mu^{*}(\lambda)(K):=\lambda\left(\left\{(i, e) \in N \times E \mid\left(i, a_{i}^{*}(e), m_{i}\left(e, a_{i}^{*}(e), \alpha^{*}(\lambda)\right)\right) \in K\right\}\right)
$$

for every measurable subset $K \subset N \times A \times M$.

\subsection{An Equivalent Direct Mechanism}

For each agent $i \in N$ there are now two equivalent direct mechanisms, one for each period. That for the first period is

$$
f_{i 1}(\lambda, e):=\xi_{i 1}^{0}\left(a_{i}^{*}(e), \alpha^{*}(\lambda)\right): \Delta(N \times E) \times E \mapsto \Re
$$

and that for the second period is

$$
f_{i 2}^{M}(\lambda, e ; m):=\xi_{i 2}^{M}\left(a_{i}^{*}(e), m, \mu^{*}(\lambda)\right): \Delta(N \times E) \times E \times M \mapsto \Re
$$

But also, given the game form and dominant strategy function specified above, each agent $i \in N$ has an equivalent direct monitoring function defined by

$$
g_{i}\left(\lambda, e^{\prime} ; e\right):=m_{i}\left(e, a_{i}^{*}\left(e^{\prime}\right), \alpha^{*}(\lambda)\right): \Delta(N \times E) \times E \times E \mapsto M
$$

So the value of $g_{i}\left(\lambda, e^{\prime} ; e\right)$ is the monitoring signal generated when agent $i$ acts as if his endowment were $e^{\prime}$ when it is really $e$, and when the joint distribution of all agents' names and endowments appears to be $\lambda$. There is then an even more direct second period mechanism $f_{i 2}\left(\lambda, e^{\prime} ; e\right): \Delta(N \times E) \times E \times E \mapsto \Re$ given by:

$$
\begin{aligned}
f_{i 2}\left(\lambda, e^{\prime} ; e\right) & :=\xi_{i 2}\left(a_{i}^{*}\left(e^{\prime}\right), e, \sigma^{*}(\lambda)\right) \equiv \xi_{i 2}^{M}\left(a_{i}^{*}\left(e^{\prime}\right), m_{i}\left(e, a_{i}^{*}\left(e^{\prime}\right), \alpha^{*}(\lambda)\right), \mu^{*}(\lambda)\right) \\
& \equiv \xi_{i 2}^{M}\left(a_{i}^{*}\left(e^{\prime}\right), g_{i}\left(\lambda, e^{\prime} ; e\right), \mu^{*}(\lambda)\right) \equiv f_{i 2}^{M}\left(\lambda, e^{\prime} ; g_{i}\left(\lambda, e^{\prime} ; e\right)\right)
\end{aligned}
$$

So $\left(f_{i 1}\left(\lambda, e^{\prime}\right), f_{i 2}\left(\lambda, e^{\prime} ; e\right)\right)$ is the net expenditure stream which results when agent $i$ acts as though his second period endowment were $e^{\prime}$ when it is really $e$, and if the joint distribution of names and endowments appears to be $\lambda$.

Note how the first period net borrowing $f_{i 1}\left(\lambda, e^{\prime}\right)$ of somebody who acts as though their second period endowment were $e^{\prime}$ must be independent of the true 
endowment $e$, because $e$ is unable to influence the monitoring signal $m \in M$ until the second period, and so can affect only the second period allocation. Of course $f_{i 2}\left(\lambda, e^{\prime} ; e\right)$ does depend, in general, not only upon the apparent value $e^{\prime}$ of the agent's endowment, but also upon the true endowment $e$, since that ultimately influences the monitoring signal $m \in M$. But it must be independent of $e$ for those true second period endowments satisfying $g_{i}\left(\lambda, e^{\prime} ; e\right)=m_{0}$, because then no monitoring occurs even in the second period.

\subsection{Incentive and Individual Feasibility Constraints}

Because of our assumption (13) that $a_{i}^{*}(e)$ is always a dominant strategy for each agent $i \in N$, one has

$$
\begin{aligned}
u\left(\xi_{i 1}^{0}\left(a_{i}^{*}(e), \alpha^{*}(\lambda)\right)+1, \xi_{i 2}\left(a_{i}^{*}\left(e^{\prime}\right), e, \sigma^{*}(\lambda)\right)+e\right) \\
\quad \leq u\left(\xi_{i 1}^{0}\left(a_{i}^{*}(e), \alpha^{*}(\lambda)\right)+1, \xi_{i 2}\left(a_{i}^{*}(e), e, \sigma^{*}(\lambda)\right)+e\right)
\end{aligned}
$$

for all $\left(\lambda, e^{\prime}, e\right)$. Then it follows immediately from (17) and (20) that

$$
u\left(f_{i 1}\left(\lambda, e^{\prime}\right)+1, f_{i 2}\left(\lambda, e^{\prime} ; e\right)+e\right) \leq u\left(f_{i 1}(\lambda, e)+1, f_{i 2}(\lambda, e ; e)+e\right)
$$

for all $\left(\lambda, e^{\prime}, e\right)$. These are precisely the incentive constraints needed for truthtelling to be a dominant strategy in the direct revelation game form induced by the direct mechanism $\left(f_{i 1}\left(\lambda, e^{\prime}\right), f_{i 2}\left(\lambda, e^{\prime} ; e\right)\right)$.

Because of (10), it must also be true that

$$
\xi_{i 2}\left(a_{i}^{*}\left(e^{\prime}\right), e, \sigma^{*}(\lambda)\right)+e \geq 0
$$

for all $\left(\lambda, e^{\prime}, e\right)$. But then (20) implies that, for all $\left(\lambda, e^{\prime}, e\right)$, the equivalent direct mechanism must satisfy the important additional individual feasibility constraint

$$
f_{i 2}\left(\lambda, e^{\prime} ; e\right)+e \geq 0 \text {. }
$$

In our simple sequence economy, the constraints (22) and (24) must all be satisfied if a direct mechanism is to be implementable in dominant strategies. Satisfying the incentive constraints (22) alone is not enough. 


\subsection{Pareto Efficient Mechanisms}

Now that the physical feasibility and incentive constraints have all been specified, it is possible in principle to describe Pareto efficient mechanisms which satisfy these constraints. The choice variables are the first period allocation mechanism $f_{i 1}(\lambda, e)$ and then, in the second period, the combination consisting of the space $M$ of monitoring signals, the monitoring function $g_{i}\left(\lambda, e^{\prime} ; e\right)$, and finally the second period allocation mechanism $f_{i 2}^{M}\left(\lambda, e^{\prime} ; m\right)$ based on these monitoring signals. The latter allocation mechanism gives rise to the function $f_{i 2}\left(\lambda, e^{\prime} ; e\right) \equiv x_{i 2}^{M}\left(\lambda, e^{\prime} ; g_{i}\left(\lambda, e^{\prime} ; e\right)\right)$.

For each possible distribution $\lambda \in \Delta(N \times E)$, a Pareto efficient mechanism will usually maximize an objective which can be expressed as a utility integral

$$
W \equiv \int_{N \times E} \omega_{i}(\lambda, e) u\left(f_{i 1}(\lambda, e)+1, f_{i 2}(\lambda, e ; e)+e\right) \lambda(d i \times d e)
$$

with welfare weights $\omega_{i}(\lambda, e)$. This should then be maximized subject to the individual feasibility constraints (24), the incentive constraints (22), and then resource balance constraints such as

$$
\begin{gathered}
\int_{N \times E} f_{i 1}(\lambda, e) \lambda(d i \times d e) \leq y_{1} \\
\int_{N \times E} f_{i 2}(\lambda, e ; e) \lambda(d i \times d e) \leq y_{2}\left(y_{1}\right)-\int_{N \times E} \gamma_{i}^{M}(\lambda, e ; e) \lambda(d i \times d e)
\end{gathered}
$$

for each of the two periods. Here, the function $\gamma_{i}^{M}\left(\lambda, e^{\prime} ; e\right)$ indicates the (non negative) resource cost of monitoring, which can be assumed to satisfy the condition that $\gamma_{i}^{M}\left(\lambda, e^{\prime} ; e\right)=0$ whenever $g_{i}\left(\lambda, e^{\prime} ; e\right)=m_{0}$ - i.e., the resource cost of the null signal is zero, so that monitoring should be avoided if possible. Nevertheless, it is quite possible that monitoring will occur for some agents even when they use their (truthful) dominant strategies. Indeed, monitoring of endowments could be part of an optimal solution even if there were no problem of default: it could simply be the most cost effective incentive compatible method of arranging the redistribution necessary as part of a particular incentive-constrained Pareto efficient allocation mechanism. After all, if monitoring of endowments were both 
perfect and costless, it would be used to bring about a first-best in every possible economic environment.

Although the problem of finding an incentive-constrained Pareto efficient allocation mechanism has now been formulated in a fairly simple way, its solution seems to be very far from simple, even in very special cases such as when the set $E$ of possible endowments has only two values. Thus the characterization of such solutions has had to be left for later work. No doubt this will build on important insights such as those in Harris and Raviv (1979), Townsend (1979), Gale and Hellwig (1985), as well as more recent unpublished work by several authors.

\section{When Can Monitoring Be Avoided in Equilibrium?}

\subsection{Incentive Constraints without Monitoring}

This section will examine the conditions under which there is (almost) no monitoring in the economy when (almost) all agents use their dominant strategies in the game form. After all, if monitoring is costly, and if the second period resource balance constraint is tight even in the absence of monitoring - as it presumably should be for an optimal mechanism - then there cannot be any monitoring at all if that mechanism is indeed to be physically feasible.

To this end, first define the function

$$
f_{i 2}^{0}(\lambda, e):=f_{i 2}^{M}\left(\lambda, e ; m_{0}\right): \Delta(N \times E) \times E \mapsto \Re .
$$

This is the second period allocation in the event of their being no monitoring. In terms of the equivalent direct mechanism, in which agents reveal their true endowments in equilibrium, there will be no monitoring in equilibrium provided that, for all $e \in E$, one has

$$
g_{i}(\lambda, e ; e)=m_{0} \quad \text { and } \quad f_{i 2}(\lambda, e ; e)=f_{i 2}^{M}\left(\lambda, e, m_{0}\right)=f_{i 2}^{0}(\lambda, e) .
$$

Now suppose that a typical agent $i \in N$ acts as though having endowment $e^{\prime}$ even though the true endowment is $e$. If agent $i$ is not monitored in the second 
period either when his endowment is $e$ or when it is $e^{\prime}$, this deception can never be detected because monitoring is the only way of noticing the difference between these two endowment levels. But because of (28), an agent whose endowment appears to be either $e$ or $e^{\prime}$ will not be monitored in dominant strategy equilibrium when those endowments are the real ones, and when $\lambda \in \Delta(N \times E)$ is the real joint distribution of names and endowments. Thus the only way in which this deception can ever be detected is if it triggers monitoring because it leads to default. In other words, if agent $i$ acts as though his endowment were $e^{t}$ when it is really $e$, there will be no monitoring unless $f_{i 2}^{0}\left(\lambda, e^{\prime}\right)+e<0$, which is precisely when agent $i$ will have to default and so trigger monitoring. So (28) implies that

$$
\begin{gathered}
g_{i}\left(\lambda, e^{\prime} ; e\right)=m_{0} \text { and } f_{i 2}\left(\lambda, e^{\prime} ; e\right)=f_{i 2}^{M}\left(\lambda, e^{\prime}, m_{0}\right)=f_{i 2}^{0}\left(\lambda, e^{\prime}\right) \\
\Longleftrightarrow f_{i 2}^{0}\left(\lambda, e^{\prime}\right)+e \geq 0 .
\end{gathered}
$$

Thus active monitoring occurs if and only if it is needed to ensure individual feasibility in the second period.

Notice how (29) implies that, if $f_{i 2}^{0}\left(\lambda, e^{\prime}\right)+e \geq 0$ and the incentive constraints (22) are also satisfied, then

$$
\begin{aligned}
u\left(f_{i 1}\left(\lambda, e^{\prime}\right)+1, f_{i 2}^{0}\left(\lambda, e^{\prime}\right)+e\right) & =u\left(f_{i 1}\left(\lambda, e^{\prime}\right)+1, f_{i 2}\left(\lambda, e^{\prime} ; e\right)+e\right) \\
\leq u\left(f_{i 1}(\lambda, e)+1, f_{i 2}(\lambda, e ; e)+e\right) & =u\left(f_{i 1}(\lambda, e)+1, f_{i 2}^{0}(\lambda, e)+e\right) .
\end{aligned}
$$

In particular, this shows that the implication

$$
\begin{aligned}
f_{i 2}^{0}\left(\lambda, e^{\prime}\right)+e & \geq 0 \Longrightarrow \\
u\left(f_{i 1}\left(\lambda, e^{\prime}\right)+1, f_{i 2}^{0}\left(\lambda, e^{\prime}\right)+e\right) & \leq u\left(f_{i 1}(\lambda, e)+1, f_{i 2}^{0}(\lambda, e)+e\right)
\end{aligned}
$$

must be true for all pairs $e, e^{\prime} \in E$. These are "restricted" incentive constraints in the sense that they need only be satisfied for those deviations $e^{\prime}$ which result in individually feasible net expenditure streams $\left(f_{i 1}\left(\lambda, e^{\prime}\right), f_{i 2}^{0}\left(\lambda, e^{\prime}\right)\right)$. Incentive constraints involving deviations which lead to individually infeasible allocations are simply ignored. For the case of static economies this corresponds precisely to the assumption made in Hammond $(1979,1987 \mathrm{a})$, in Gale $(1980,1982)$, and apparently in Postlewaite and Schmeidler $(1986,1987)$ too. 
It is therefore especially important to understand clearly the difference between (31) and the earlier combination of the incentive constraints (22) with the individual feasibility constraints (24). Because of the need to ensure individual feasibility, through monitoring if necessary, each individual's second period net expenditure $f_{i 2}\left(\lambda, e^{\prime} ; e\right)$ in (22) depends on both $e^{\prime}$ and $e$ (as well as on $\lambda$, of course), and the incentive constraints are required to hold for all possible pairs $e, e^{\prime}$. Whereas (31) restricts attention to just those pairs $e, e^{\prime}$ for which the individual feasibility constraint $f_{i 2}^{0}\left(\lambda, e^{\prime}\right)+e \geq 0$ is satisfied anyway, and does not need to make $f_{i 2}^{0}\left(\lambda, e^{\prime}\right)$ depend on $e$ as well as on $e^{\prime}$.

Note too how, when (28) holds, then the incentive constraints (22) must implicitly include "deterrence constraints" ensuring that, if agent $i$ defaults in the second period and so allows monitoring to be triggered, then allocating $i$ the net expenditure level $f_{i 2}^{M}\left(\lambda, e^{\prime} ; m\right)$ with $m \neq m_{0}$ is an effective punishment ensuring that there are no benefits to default. So, if (28) could be made true, not only would truthful revelation always be a dominant strategy, but it would also follow that monitoring is never necessary when individuals do reveal their true endowments.

\subsection{Sufficient and Necessary Conditions}

Second period consumption $f_{i 2}\left(\lambda, e^{\prime} ; e\right)+e$ must always be non-negative, however, even if all of a defaulter's endowment is monitored and then confiscated. Since utility is strictly increasing, combining (28) with the incentive constraints (22) implies that, for all pairs $e, e^{\prime} \in E$, one has

$$
\begin{aligned}
u\left(f_{i 1}\left(\lambda, e^{\prime}\right)+1,0\right) & \leq u\left(f_{i 1}\left(\lambda, e^{\prime}\right)+1, f_{i 2}\left(\lambda, e^{\prime} ; e\right)+e\right) \\
& \leq u\left(f_{i 1}(\lambda, e)+1, f_{i 2}(\lambda, e ; e)+e\right) \\
& =u\left(f_{i 1}(\lambda, e)+1, f_{i 2}^{0}(\lambda, e)+e\right)
\end{aligned}
$$

Some strong sufficient conditions for this key property (32) to hold are that $f_{i 1}(\lambda, e)+1>0$ and $f_{i 2}^{0}(\lambda, e)+e>0$ for all $e \in E$, and also that

$$
u\left(c_{1}^{\prime}, 0\right) \leq u\left(c_{1}, c_{2}\right) \text { whenever } \quad c_{1}^{\prime} \geq 0 \text { and } c_{1}, c_{2}>0 .
$$


This will be true in particular when preferences are "smooth", implying that no indifference curve intersects the $c_{2}=0$ axis. When (33) is satisfied, (32), (22) and (24) can indeed all be made true provided that any defaulter's second period consumption gets reduced to zero by means of a mechanism such as (11). In this special case, then, there will be no need for monitoring in equilibrium, when all agents do use their dominant strategies.

In general two period economies, the ability to satisfy the incentive constraints (22) and the feasibility constraints (24) in all cases, without the need for any monitoring, rests on much stronger assumptions than it does in a single period economy. If the economy lasts for only one period, then cutting off defaulters from all trading opportunities is often an effective deterrent. In our two period economy, however, any monitoring occurs only in the second period and so leaves the first period allocation unaffected. Thus defaulters can be punished only in the second period, by which time it may be too late. In particular, a borrower has most likely already spent what was borrowed, and imposing zero net expenditure in the second period only is tantamount to forgiveness of any debt.

Indeed, if it happens to be true that zero consumption (or whatever other lower bound is imposed on defaulters) is not too bad, perhaps because the defaulter is no longer in a position to care very much anyway, then the necessary condition (32) for deterring all default imposes an upper bound on $f_{i 1}\left(\lambda, e^{\prime}\right)$. For the specific case when

$$
u\left(c_{1}, c_{2}\right) \equiv \sqrt{c_{1}}+\sqrt{c_{2}}
$$

for instance, (32) obviously implies that

$$
\sup _{e^{\prime} \in E}\left\{f_{i 1}\left(\lambda, e^{\prime}\right)\right\} \leq \inf _{e \in E}\left\{\left(\sqrt{f_{i 1}(\lambda, e)+1}+\sqrt{f_{i 2}^{0}(\lambda, e)+e}\right)^{2}-1\right\}
$$

for almost all $i \in N$. This necessary condition for the absence of default when agents use their dominant strategies need not be true even for the usual kind of Walrasian mechanism, with budget sets given by the familiar

$$
c_{1}+(1+r)^{-1} c_{2} \leq 1+(1+r)^{-1} e
$$


for a suitable rate of interest $r$. For in a pure exchange economy with utility function given by (34), the appropriate unique Walrasian equilibrium is symmetric, with net expenditures and an interest rate which are easily calculated as being given by the functions

$$
f_{i 1}(\lambda, e) \equiv \frac{e-\bar{e}(\lambda)}{\bar{e}(\lambda)+\sqrt{\bar{e}(\lambda)}} ; \quad f_{i 2}^{0}(\lambda, e) \equiv \frac{\bar{e}(\lambda)-e}{\sqrt{\bar{e}(\lambda)}+1} ; \quad r(\lambda) \equiv \sqrt{\bar{e}(\lambda)}-1 .
$$

Here $\bar{e}(\lambda)$ denotes the mean second period endowment $\int_{N \times E} e \lambda(d i \times d e)$. In this case it is easy to check that (35) is satisfied if and only if

$$
\frac{e^{*}+\sqrt{\bar{e}(\lambda)}}{e_{*}+\sqrt{\bar{e}(\lambda)}} \leq(\sqrt{\bar{e}(\lambda)}+1)^{2}
$$

where $e^{*}$ and $e_{*}$ denote respectively the supremum and the infimum of the set $E$ of possible second period endowments which the allocation mechanism has to allow for. In particular, (38) is never satisfied if $e$ is lognormally distributed.

Accordingly, it seems that one has to abandon the hypothesis that, even when individuals are privately informed about their endowments, there are always dominant strategy incentive compatible mechanisms in which all defaults can be prevented, without the need for any monitoring in equilibrium. Also, even if such mechanisms do exist, it may still be true that the incentive constraints $(22)$ and feasibility constraints (24) are together strictly stronger than just (31).

\section{Decentralization}

\subsection{Construction of Budget Sets}

So consider now any incentive compatible extended direct allocation mechanism in the two period continuum economy, as in Section 3.2, which satisfies both the incentive constraints (22) and the feasibility constraints (24). Any such extended mechanism can be decentralized by allowing each agent $i \in N$ to choose from two suitable sets as follows: the first is the value of a suitable monitoring signal possibility correspondence $M_{i}(\lambda, e): \Delta(N \times E) \times E \mapsto M$; then the second is the value of a (nonlinear) budget correspondence $B_{i}^{M}(\lambda, m): \Delta(N \times E) \times M \mapsto \Re^{2}$ 
which depends upon the monitoring signal $m \in M$. Agent $i$ is free to send any signal $m \in M_{i}(\lambda, e)$ to the monitoring agent, and then to choose any net expenditure stream $x \in B_{i}^{M}(\lambda, m)$ which is consistent with that monitoring signal.

This being a two period sequence economy makes it natural, however, to have separate budget correspondences for each of the two periods. Moreover, the second period budget correspondence should be linked to the choice in the first period. So, for every $\lambda \in \Delta(N \times E), e \in E$, and $m \in M$, construct for the two (partial) functions $f_{i 1}(\lambda, e): E \mapsto \Re$ and $g_{i}\left(\lambda, e^{\prime} ; e\right): E \mapsto M$ the respective range sets $B_{i 1}(\lambda):=f_{i 1}(\lambda, E)$ and $M_{i}(\lambda, e):=g_{i}(\lambda, E ; e)$ as the endowment $e^{\prime}$ varies within the domain $E$. Also, define

$$
B_{i 2}^{M}\left(\lambda, x_{1} ; m\right):=\left\{x_{2} \in \Re \mid \exists e \in E: x_{1}=f_{i 1}(\lambda, e) ; x_{2}=f_{i 2}^{M}(\lambda, e ; m)\right\}
$$

as the set of possible second period net receipts of principal and interest which, for some endowment $e$ in the domain $E$, are consistent with the first period net borrowing level $x_{1}$ and the monitoring signal $m$. Then the incentive constraints (22) imply that, for every $\lambda \in \Delta(N \times E)$ and $e \in E$, one has

$$
\begin{aligned}
\left(f_{i 1}(\lambda, e), f_{i 2}(\lambda, e ; e),\right. & \left.g_{i}(\lambda, e ; e)\right) \\
& \in \underset{\left(x_{1}, x_{2}, m\right)}{\arg \max }\left\{u\left(x_{1}+1, x_{2}+e\right) \mid\left(x_{1}, x_{2}, m\right) \in B^{M}(\lambda, e)\right\}
\end{aligned}
$$

where $B^{M}(\lambda, \epsilon)$ denotes the set:

$$
\begin{aligned}
&\left\{\left(x_{1}, x_{2}, m\right) \in \Re^{2} \times M \mid\right. \\
&\left.\exists e^{\prime} \in E: x_{1}=f_{i 1}\left(\lambda, e^{\prime}\right) ; m=g_{i 1}\left(\lambda, e^{\prime} ; e\right) ; x_{2}=f_{i 2}^{M}\left(\lambda, e^{\prime} ; m\right)\right\} \\
&=\left\{\left(x_{1}, x_{2}, m\right) \in \Re^{2} \times M \mid x_{1} \in B_{i 1}(\lambda) ; m \in M_{i}(\lambda, e) ; x_{2} \in B_{i 2}^{M}\left(\lambda, x_{1} ; m\right)\right\} .
\end{aligned}
$$

Once again, since second period consumption $f_{i 2}\left(\lambda, e^{\prime} ; e\right)+e$ must always be non-negative, even if all of a defaulter's endowment is monitored and then confiscated, and since utility is strictly increasing, the incentive constraints (22) imply that

$$
\begin{aligned}
u\left(f_{i 1}\left(\lambda, e^{\prime}\right)+1,0\right) & \leq u\left(f_{i 1}\left(\lambda, e^{\prime}\right)+1, f_{i 2}\left(\lambda, e^{\prime} ; e\right)+e\right) \\
& \leq u\left(f_{i 1}(\lambda, e)+1, f_{i 2}(\lambda, e ; e)+e\right) .
\end{aligned}
$$


This obviously implies that

$$
\begin{aligned}
\sup _{x_{1}}\left\{u\left(x_{1}+1,0\right) \mid x_{1} \in B_{i 1}(\lambda)\right\} & =\sup _{e^{\prime} \in E}\left\{u\left(f_{i 1}\left(\lambda, e^{\prime}\right)+1,0\right)\right\} \\
& \leq \inf _{e \in E}\left\{u\left(f_{i 1}(\lambda, e)+1, f_{i 2}(\lambda, e ; e)+e\right)\right\} .
\end{aligned}
$$

So generally, unless (33) is satisfied and monitoring leads to zero consumption in the second period, there will have to be an upper bound $\bar{x}_{i 1}(\lambda)$ on $B_{i 1}(\lambda)$, the set of allowable levels of $i$ 's first period net borrowing. In particular, there must be such an upper bound for those agents who are monitored even in equilibrium.

\subsection{A Two Period Demand Revelation Game Form}

A very flexible demand revelation game form will now be defined. It is an important example of a dominant strategy mechanism satisfying incentive constraints in the presence of private information about endowments, with monitoring of defaulters.

Let $P$ denote a bounded subset of some finite dimensional Euclidean space. Suppose that each point $p \in P$ is some budget parameter vector determining a decentralization. Specifically, suppose that each $p \in P$ helps determine the following three items, all of which are taken to be independent of individuals' names:

(i) a first period net borrowing ceiling $\bar{x}_{1}(p)$, which is allowed to be infinite in case there is no credit rationing;

(ii) a continuous monitoring function $m\left(p, x_{1} ; e\right): P \times \Re \times \Re_{+} \mapsto M$ which depends on both the first period level of net borrowing $x_{1}$ and the second period endowment $e \in E$;

(iii) a continuous net expenditure function $\beta_{2}^{M}\left(p, x_{1} ; m\right): P \times \Re \times M \mapsto \Re$ for the second period which depends on both the first period level of net borrowing $x_{1}$ and on the second period monitoring signal $m \in M$.

To return to the familiar Walrasian example with a budget set of the form (36), where the only parameter $p$ is the interest rate $r$, the second period net 
expenditure function in the absence of monitoring would of course be given by

$$
\beta_{2}^{M}\left(r, x_{1} ; m_{0}\right) \equiv-(1+r) x_{1}
$$

Notice how, given the monitoring and second period net expenditure functions as in (ii) and (iii) above, $x_{2}$ is given by the continuous composite function

$$
\beta_{2}\left(p, x_{1}, e\right):=\beta_{2}^{M}\left(p, x_{1} ; m\left(p, x_{1} ; e\right)\right) .
$$

In order to ensure that individual feasibility is satisfied, assume that

$$
\beta_{2}\left(p, x_{1} ; e\right)+e \geq 0
$$

for all $p \in P, x_{1} \in\left[-1, \bar{x}_{1}(p)\right]$, and $e \in E$. As in (29) above, it would also be desirable here to have

$$
m\left(p, x_{1} ; e\right)=m_{0} \Longleftrightarrow \beta_{2}^{M}\left(p, x_{1} ; m_{0}\right)+e \geq 0
$$

for all such $p, x_{1}$, and $e$. Then there is no monitoring except in those cases when it is really necessary to ensure individual feasibility. Such an assumption plays no role in the following analysis, however, and may anyway be too restrictive for the reasons discussed in Section 4.2 above.

Consider now the game form in which each agent's common strategy space $A$ is the set $\mathcal{D}$ consisting of all first period net demand or net borrowing correspondences $D(\cdot): P \mapsto \Re$ which satisfy the condition that $\emptyset \neq D(p) \subset\left[-1, \bar{x}_{1}(p)\right]$ everywhere in their domain $P$, and which also have closed graphs in the product set $P \times \Re$. In the Walrasian case mentioned above, these two conditions will be true of the usual utility maximizing demand correspondence provided that the endowment stream $(1, e)$ is in the interior of the consumption set $C$, as is well known.

Note how it suffices for each individual to announce only a first period net demand correspondence because, once $x_{1}$ has been specified, then $m$ is automatically determined by the function $m\left(p, x_{1}, e\right)$, and so is $x_{2}$ by the function $\beta_{2}^{M}\left(p, x_{1} ; m\right)$ or by the function $\beta_{2}\left(p, x_{1} ; e\right)$ as in (45) above. 
Under the above assumptions $\mathcal{D}$ is itself a measurable space, because it can be identified with the set of all closed subsets of $P \times \Re$. So it can be given the Hausdorff metric and the associated Borel $\sigma$-algebra. Thus the space $\Delta(N \times \mathcal{D})$ of joint distributions of agents' names and their strategies or demand correspondences is well defined.

Let $\delta \in \Delta(N \times \mathcal{D})$ denote such a joint distribution. Suppose that there is a "market-clearing" budget parameter function $p^{*}(\delta): \Delta(N \times \mathcal{D}) \mapsto P$ defined for each such distribution. Suppose then that the first period net borrowing of each agent $i \in N$ is given by the demand selection rule $d_{i 1}(D(\cdot), \delta): \mathcal{D} \times \Delta(N \times \mathcal{D}) \mapsto \Re$ which is defined to satisfy the condition that $d_{i 1}(D(\cdot), \delta) \in D\left(p^{*}(\delta)\right)$ throughout its domain. Notice that $d_{i 1}$ is independent of $e$ so that no use is made of information which is private to agent $i$ in the first period. Then the associated second period net expenditure is

$$
\left.d_{i 2}(D(\cdot), \delta, e)\right):=\beta_{2}\left(p^{*}(\delta), d_{i 1}(D(\cdot), \delta) ; e\right): \mathcal{D} \times \Delta(N \times \mathcal{D}) \times E \mapsto \Re,
$$

where $\beta_{2}(\cdot)$ is given by (45).

For each joint distribution $\sigma \in \Delta(N \times E \times \mathcal{D})$ of names, endowments, and announced demand correspondences, the resource balance constraints in each of the two periods can be expressed as:

$$
\begin{gathered}
\int_{N \times \mathcal{D}} d_{i 1}(D(\cdot), \delta) \delta(d i \times d D) \leq y_{1} \\
\left.\int_{N \times \mathcal{D} \times E} d_{i 2}(D(\cdot), \delta, e)\right) \sigma(d i \times d D \times d e) \leq y_{2}\left(y_{1}, \sigma\right) .
\end{gathered}
$$

Note that the second constraint allows for monitoring costs, since the distribution $\sigma$ determines what monitoring activities take place and so what these costs will be. It is naturally assumed that the functions $p^{*}(\delta)$ and $d_{i 1}(D(\cdot), \delta)$ are selected to satisfy both constraints of (49), preferably with equality so that no resources are wasted. This completes the description of the two period demand revelation game form. 


\subsection{Dominant Strategies}

Now suppose that $\bar{x}_{1}(p)$ is finite for every $p \in P$. Provided that (49) can indeed be satisfied by a mechanism of this form, this demand revelation game form then satisfies all our earlier assumptions. Each agent $i \in N$ has a dominant strategy of announcing the true utility maximizing first period net demand correspondence $D^{*}(\cdot ; e): P \mapsto \Re$ of somebody who knows that his second period endowment will be $e$. This, of course, is given by

$$
D^{*}(p ; e):=\underset{x_{1}}{\arg \max }\left\{u\left(x_{1}+1, \beta_{2}\left(p, x_{1} ; e\right)+e\right) \mid-1 \leq x_{1} \leq \bar{x}_{1}(p)\right\}
$$

for all $p \in P$ and $e \in E$. Note that $D^{*}(p ; e)$ could well be empty if $\bar{x}_{1}(p)$ were allowed to be infinite, unless both (33) is satisfied and also $\beta_{2}\left(p, x_{1} ; e\right)+e$ becomes zero when $x_{1}$ is large enough.

Announcing the true first period net demand correspondence $D^{*}(\cdot ; e)$ is a dominant strategy in any game form of this kind because, if any other first period demand correspondence $D(\cdot) \in \mathcal{D}$ were announced instead, the agent would risk being allocated a level of net borrowing in the first period which is suboptimal for the budget parameter vector $p^{*}(\delta)$. Whereas an optimal level of net borrowing $\left.d_{i 1}\left(D^{*}\left(p^{*}(\delta)\right), \delta\right)\right)$ is available if the true first period demand correspondence is announced. And, because of the way that the monitoring and second period net repayment functions have been constructed, there is no way for any agent to announce a false first period demand correspondence which eventually results in individual infeasibility. So this demand revelation game form does indeed give rise to truthful revelation of one's demand correspondence as a dominant strategy. Unless (32) is satisfied, however, even truthful revelation may give rise to monitoring. This is because agents who would otherwise have very low consumption in the first period will borrow intending to default and to expose themselves to such monitoring. Also, unless (32) is satisfied, equilibrium is only possible if $\bar{x}_{1}(p)$ is finite, implying that there is credit rationing. For this is the only way of limiting the otherwise insatiable demands for first period credit of those whose dominant strategy is to default in the second period. 
Let $\delta^{*}(\lambda) \in \Delta(N \times \mathcal{D})$ denote the joint distribution of names and of true utility-maximizing demand correspondences in the population when the joint distribution of names and true endowments is $\lambda \in \Delta(N \times E)$. When individuals use their dominant strategies of announcing their true utility maximizing demand correspondences, the equivalent direct mechanism which results takes the form:

$$
\begin{aligned}
f_{i 1}(\lambda, e) & :=d_{i 1}\left(D^{*}\left(p^{*}\left(\delta^{*}(\lambda)\right) ; e\right), \delta^{*}(\lambda)\right) ; \\
g_{i}\left(\lambda, e^{\prime} ; e\right) & :=m\left(p^{*}\left(\delta^{*}(\lambda)\right), D^{*}\left(p^{*}\left(\delta^{*}(\lambda)\right) ; e^{\prime}\right) ; e\right) ; \\
f_{2}^{M}\left(\lambda, e^{\prime} ; m\right) & :=\beta_{2}^{M}\left(p^{*}\left(\delta^{*}(\lambda)\right), d_{i 1}\left(D^{*}\left(p^{*}\left(\delta^{*}(\lambda)\right) ; e^{\prime}\right), \delta^{*}(\lambda)\right) ; m\right) ; \\
f_{i 2}\left(\lambda, e^{\prime} ; e\right) & :=d_{i 2}\left(D^{*}\left(p^{*}\left(\delta^{*}(\lambda)\right) ; e^{\prime}\right), \delta^{*}(\lambda) ; e\right) .
\end{aligned}
$$

For this equivalent direct mechanism, truthful revelation of endowments is always a dominant strategy for every agent. In fact, because condition (46) has been imposed on the demand revelation game form, this equivalent direct mechanism satisfies both the incentive constraints (22) and the individual feasibility constraints (24).

\subsection{A Special Case}

A particular demand revelation mechanism of some interest is when each $p \in P$ is a pair $\left(r, \bar{x}_{1}\right)$ consisting of an interest rate $r$ together with a first period borrowing ceiling $\bar{x}_{1}$, and when (44) and (11) are both satisfied. Then capital markets have just two "imperfections": first, those who want to borrow large amounts may find their credit being rationed; second, there may be some default, even though defaulters have their second period consumption reduced to zero. In this special case, the utility-maximizing first period net demand correspondence is

$$
D^{*}\left(r, \bar{x}_{1} ; e\right) \equiv \underset{x_{1}}{\arg \max }\left\{u\left(x_{1}+1, \max \left\{0, e-(1+r) x_{1}\right\}\right) \mid-1 \leq x_{1} \leq \bar{x}_{1}\right\} .
$$

Note that $D^{*}\left(r, \bar{x}_{1} ; e\right)$ will equal to $\bar{x}_{1}$, with the agent facing zero consumption in the second period, whenever the "default" utility level $u\left(x_{1}+1,0\right)$ exceeds the usual indirect utility

$$
V(r ; e):=\max _{x_{1}}\left\{u\left(x_{1}+1, x_{2}+e\right) \mid x_{1}+(1+r) x_{2} \leq 0\right\}
$$


from optimizing subject to the Walrasian budget constraint. Of course, those agents who are induced to borrow more than they can repay at the rate of interest $r$ must be among those who have their credit rationed, since otherwise their demands for first period consumption would be unlimited.

Some typical properties of the first period net demand correspondence $D^{*}$ can be illustrated by taking the specific utility function (34), for which

$$
D^{*}\left(r, \bar{x}_{1} ; e\right) \equiv \underset{x_{1}}{\arg \max }\left\{\sqrt{x_{1}+1}+\max \left\{0, \sqrt{e-(1+r) x_{1}}\right\} \mid-1 \leq x_{1} \leq \bar{x}_{1}\right\} .
$$

There are now three cases to consider. The first (case W) is the usual Walrasian case, in which the credit ceiling does not bind and the agent repays in full. In this case $D^{*}\left(r, \bar{x}_{1} ; e\right)=\left\{x_{1}^{W}\right\}$, where

$$
x_{1}^{W}:=\frac{e-(1+r)^{2}}{(1+r)(2+r)}
$$

and the indirect utility function is

$$
V^{W}(r ; e):=\sqrt{(2+r)\left[1+(1+r)^{-1} e\right]}
$$

Agents in this case are borrowers or lenders according to whether $e$ is greater or less than $(1+r)^{2}$. The second (case $\mathrm{R}$ ) occurs when the individual's credit is rationed, but that credit is repaid. Then $D^{*}\left(r, \bar{x}_{1} ; e\right)=\left\{\bar{x}_{1}\right\}$ and $e-(1+r) \bar{x}_{1} \geq 0$. This occurs when

$$
e>(1+r)^{2}+(1+r)(2+r) \bar{x}_{1}
$$

because then (55) implies that the Walrasian $x_{1}^{W}$ net demand exceeds the ceiling $\bar{x}_{1}$. The third (case D) occurs when the agent borrows more than can be repaid. For this case too credit is rationed, so $D^{*}\left(r, \bar{x}_{1} ; e\right)=\left\{\bar{x}_{1}\right\}$, but now $e-(1+r) \bar{x}_{1}<$ 0 . This case occurs when

$$
e<(2+r)^{-1}(1+r)\left[\bar{x}_{1}-(1+r)\right]
$$

because then the Walrasian indirect utility $V^{W}(r ; e)$ given by $(56)$ is less than the default utility $\sqrt{\bar{x}_{1}+1}$, even after second period consumption has been reduced 
to zero. It should be noted finally that case W will occur on a non-trivial interval of values of $e$ if $\bar{x}_{1}+1>0$, because this is sufficient to ensure that the lower limit determined by (58) is less than the upper limit determined by (57).

\subsection{A Two Type Example}

Let us now restrict this special example further by assuming that the set of possible endowments $E$ is just the pair $\left\{0, e^{*}\right\}$, and that $e^{*}$ occurs with probability $\pi$ throughout the population, while the probability of a zero endowment in the second period is $1-\pi$. Then the mean endowment is $\pi e^{*}$. So, according to (37), the unique Walrasian equilibrium for this distribution $\lambda$ has the interest rate $r=\sqrt{\pi e^{*}}-1$ and (in an obvious notation) the allocation

$$
\begin{array}{ll}
x_{1}\left(e^{*}\right)=\frac{e^{*}-\pi e^{*}}{\pi e^{*}+\sqrt{\pi e^{*}} ;} & x_{2}\left(e^{*}\right)=\frac{\pi e^{*}-e^{*}}{\sqrt{\pi e^{*}}+1} ; \\
x_{1}(0)=\frac{-\pi e^{*}}{\pi e^{*}+\sqrt{\pi e^{*}}} ; & x_{2}(0)=\frac{\pi e^{*}}{\sqrt{\pi e^{*}}+1} .
\end{array}
$$

Thus those with zero second period endowment save by making loans to those with $e^{*}$ so that both types of agent have positive consumption in both periods.

Also, according to (38), this unique Walrasian equilibrium is unsustainable in case $e^{*}+\sqrt{\pi e^{*}}>\sqrt{\pi e^{*}}\left(\sqrt{\pi e^{*}}+1\right)^{2}$, which is true iff $\pi^{-1}-2>\sqrt{\pi e^{*}}$ or iff $\pi<\frac{1}{2}$ and $e^{*}<(1-2 \pi)^{2} \pi^{-3}$. Recall that the unsustainability arises because agents with zero second period endowment prefer the consumption stream which they can get by borrowing like an agent with $e^{*}$ and then defaulting in the second period to the consumption stream which they can get by being "honest."

When this Walrasian allocation is unsustainable, we shall look for an alternative allocation, with a borrowing rate $r_{B}$ and a lending rate $r$. There will also be a credit ceiling $\bar{x}_{1}$ imposed to prevent those with zero second period endowment from borrowing with the intention to default. In addition, agents who do not default in the second period will receive a dividend $m$ which is financed by profits earned from the difference between the borrowing and lending rates of interest. Those with zero second period endowment will still be lending to those with $e^{*}$. And even though the need to allow for default prevents attainment of the Walrasian allocation, there will actually be no default in the new equilibrium. The 
need for differential borrowing and lending rates will also be demonstrated, in the case when the Walrasian equilibrium is unsustainable.

Since individuals with $e=0$ are lending, the credit ceiling does not affect them at all (except to deter borrowing with intent to default), and so their net borrowing is at the Walrasian level given by

$$
x_{1}^{W}(0)=\frac{m-(1+r)^{2}}{(1+r)(2+r)},
$$

after changing (55) above to take account of the dividend $m$ in the second period, and then putting $e=0$. The net repayment of each such individual, in the event of no default, is

$$
x_{2}^{W}(0)=m-(1+r) x_{1}^{W}(0)=\frac{(m+1+r)(1+r)}{2+r} .
$$

The associated utility level is

$$
u^{W}(0)=\sqrt{\frac{(m+1+r)(2+r)}{1+r}} .
$$

Individuals with $e=e^{*}$ are credit constrained, on the other hand, and so have $x_{1}\left(e^{*}\right)=\bar{x}_{1}$ and $x_{2}\left(e^{*}\right)=\bar{x}_{2}=m-\left(1+r_{B}\right) \bar{x}_{1}$. Then the two market clearing conditions $\pi x_{t}\left(e^{*}\right)+(1-\pi) x_{t}(0)=0$ in each of the two periods $t=1$ and $t=2$ obviously require that

$$
\bar{x}_{t}=-(1-\pi) x_{t}^{W}(0) / \pi .
$$

But then the borrowing rate of interest must be given by

$$
1+r_{B}=\frac{m-\bar{x}_{2}}{\bar{x}_{1}}=1+r+\frac{(1+r)(2+r) m}{(1-\pi)\left[(1+r)^{2}-m\right]},
$$

as can be shown by routine manipulation. In particular, this shows that the borrowing rate succeeds the lending rate if and only if the dividend $m$ is positive, and also that $r_{B}$ must increase whenever $m$ increases.

Default will be deterred provided that the (indirect) utility (62) of those with $e=0$ does not fall below $\sqrt{\bar{x}_{1}+1}$. So we must have

$$
m \geq \underline{m}(r):=\frac{(1+r)^{2}[1-\pi(3+r)]}{1+\pi(1+r)(3+r)} .
$$


In order to have an equilibrium, it must be true that agents with $e=e^{*}$ are borrowing no more than they wish. Thus their marginal rate of substitution $\left(1+\bar{x}_{1}\right)^{-\frac{1}{2}} /\left(e^{*}+\bar{x}_{2}\right)^{-\frac{1}{2}}$ at the consumption stream $\left(1+\bar{x}_{1}, e^{*}+\bar{x}_{2}\right)$ cannot be less than the borrowing interest factor $1+r_{B}$. This is true iff

$$
e^{*} \geq\left(1+r_{B}\right)^{2}\left(1+\bar{x}_{1}\right)-\bar{x}_{2} .
$$

Some routine manipulation establishes that, for each fixed rate of interest $r$ on loans, the right hand side of (66) is an increasing function of $m$, so this inequality serves to define an upper bound $\bar{m}\left(e^{*}, r\right)$ on allowable values of $m$. Of course, (66) also ensures that $e^{*}+\bar{x}_{2} \geq 0$, thus guaranteeing individual feasibility.

So all allocations of this form are sustainable provided that $m$ satisfies $\underline{m}(r) \leq$ $m \leq \bar{m}\left(e^{*}, r\right)$ for the chosen lending rate $r$, and provided that the credit ceiling and borrowing rate are then determined by (63) and (64) respectively. It remains to be shown that the borrowing rate must succeed the lending rate in the case when the Walrasian equilibrium is unsustainable. Indeed, suppose it were true that $m=0$ and so $r_{B}=r$. Then (65) clearly implies that $0 \geq 1-\pi(3+r)$ or that $1+r \geq \max \left\{0, \pi^{-1}-2\right\}$. But when $m=0,(66)$ reduces to $\pi e^{*} \geq(1+r)^{2}$, and so an equilibrium of this particular form exists for interest rates in the range satisfying

$$
\max \left\{0, \pi^{-1}-2\right\} \leq 1+r \leq \sqrt{\pi e^{*}}
$$

In the case when $\pi \geq \frac{1}{2}$, such equilibria exist for all positive values of $e^{*}$. But when $\pi<\frac{1}{2}$, such equilibria exist only if and only if $e^{*} \geq(1-2 \pi)^{2} \pi^{-3}$, which is precisely the condition for Walrasian equilibrium to be sustainable anyway. This proves the assertion: when Walrasian equilibrium is unsustainable, a nonWalrasian equilibrium of the kind considered here can only be sustained by means of a positive gap between borrowing and lending rates of interest. 


\section{Conclusion: Perfect Capital Markets are Generally Not Possible}

This paper has considered borrowing and lending in the simplest of all possible models, in which capital markets have the best chance of performing perfectly because there is a continuum of agents. There are no jointly owned private producers and no uncertainty - just an exchange economy lasting for only two periods with a single consumption good, in which agents have the same utility function and the same known first period endowment. It was also assumed that all agents know in the first period what their second period endowment will be, but this is private information. Apart from the continuum of agents, none of these features of the model is important except insofar as they help to concentrate on essentials.

Of much more significance is the assumption that (33) is violated. This requires that the consumers' common utility function $u\left(c_{1}, c_{2}\right)$ for two period consumption streams satisfy the condition $u\left(c_{1}^{\prime}, 0\right)>u\left(c_{1}, c_{2}\right)$ for some $c_{1}^{\prime}$ which is sufficiently large. So there must be some indifference curves meeting the $c_{1}$-axis. Then the threat of imposing zero second period consumption may be ineffective. This is crucial to the specific simple model used here. But not really to the need for credit rationing, because the familiar lifetime budget constraints of more general models are clearly incredible. Indeed, even a lifetime budget constraint is just a particular borrowing constraint which purports to prohibit dying in debt.

So the model presented here illustrates rather starkly the fact that, when some information about individuals is private, "perfect capital markets" may be impossible. If agents have private information about their future endowments, then an allocation mechanism which always selects a "perfect" Walrasian equilibrium in every economic environment is generally manipulable by agents who plan deliberately to violate their Walrasian budget constraints. By contrast, in a static continuum economy, such a mechanism is not manipulable, provided only that default can be detected in time and defaulters punished by being reduced to autarky or with some other sufficient deterrent. Thus the inevitable "market failure" in these economic environments is due to the sequential nature of the economy rather than to private information per se. 
It appears that Stigler's (1967) plea for a theory behind assumed capital market imperfections can now be answered. Or, if not, that our conception of what constitutes a perfect capital market needs changing drastically to allow incentive constrained Pareto efficient allocations which generally require credit rationing, nonlinear pricing, and regulated entry into and participation in credit markets.

The model used here also has the virtue of bringing out the need to control fraud. It should be remembered that U.S. banks have been said to lose eighteen times as much from fraud as they do from robbery. And that the Federal Bureau of Investigation is reported to have fifty agents working on bank fraud cases in Los Angeles alone. ${ }^{3}$

\section{REFERENCES}

F. AlLEN (1981), "The Prevention of Default," Journal of Finance, 36: 271-276.

F. Allen (1983), "Credit Rationing and Payment Incentives," Review of Economic Studies, 50: 639-646.

K.J. Arrow AND F.H. Hahn (1971), General Competitive Analysis. San Francisco: Holden-Day.

C.J. Bliss (1976), "Capital Theory in the Short Run," in M. Brown, K. Sato and P. Zarembka (ed.), Essays in Modern Capital Theory (Amsterdam: North-Holland), pp. 187-205.

J.L. Coles AND P.J. Hammond (1986), "Walrasian Equilibrium without Survival: Existence, Efficiency, and Remedial Policy," Stanford University Institute of Mathematical Studies in the Social Sciences, Economics Technical Report No. 483.

P.S. DAsgupta And P.J. Hammond (1980), "Fully Progressive Taxation," Journal of Public Economics, 13: 141-154.

3 This is based on my own notes of a television documentary on the crisis in banking which was shown on the KQED Public Broadcasting Service station in the San Francisco Bay Area of California early in 1989. 
G. Debreu (1959), Theory of Value: An Axiomatic Analysis of Economic Equilibrium. New York: John Wiley.

P. Dubey AND M. ShubiK (1979), "Bankruptcy and Optimality in a Closed Trading Mass Economy Modeled as a Non-Cooperative Game," Journal of Mathematical Economics, 6: 115-134.

J. Eaton And M. Gersovitz (1981), "Debt with Potential Repudiation: Theoretical and Empirical Analysis," Review of Economic Studies, 48: 289-309.

M. Feldman AND C. Gilles (1985), "An Expository Note on Individual Risk without Aggregate Uncertainty," Journal of Economic Theory, 35: 26-32.

D. K. Foley ANd M. F. Hellwig (1975), "A Note on the Budget Constraint in a Model of Borrowing," Journal of Economic Theory, 11: 305-314.

D.M. Gale (1979), "Large Economies with Trading Uncertainty," Review of Economic Studies, 46: 319-338.

D.M. Gale (1980), "Money, Information and Equilibrium in Large Economies," Journal of Economic Theory, 23: 28-65.

D.M. Gale (1982), Money: In Equilibrium. Welwyn: James Nisbet.

D.M. Gale ANd M. Hellwig (1985), "Incentive-Compatible Debt Contracts: The One-Period Problem," Review of Economic Studies, 52: 647-663.

J.-M. Grandmont (1982), "Temporary General Equilibrium Theory," in K.J. Arrow and M.D. Intriligator (ed.), Handbook of Mathematical Economics, Vol. II (Amsterdam: North-Holland), ch. 19, pp. 879-922.

J.-M. Grandmont (ED.) (1988), Temporary Equilibrium: Selected Readings. San Diego: Academic Press.

E.J. GREen (1987), "Lending and the Smoothing of Uninsurable Income," in E.C. Prescott and N. Wallace (ed.), Contractual Arrangements for Intertemporal Trade (Minneapolis: University of Minnesota Press), ch. 1, pp. 3-25. 
J. R. Green (1974), "Pre-existing Contracts and Temporary General Equilibrium," in M.S. Balch, D.L. McFadden and S.Y. Wu (ed.), Essays on Economic Behavior Under Uncertainty (Amsterdam: North-Holland), ch. 10, pp. 263-286.

F.H. Hahn (1988), "On Monetary Theory," Economic Journal, 98: 957-953.

P.J. HAMMOND (1979), "Straightforward Individual Incentive Compatibility in Large Economies," Review of Economic Studies, 46: 263-282.

P.J. Hammond (1987a), "Markets as Constraints: Multilateral Incentive Compatibility in a Continuum Economy," Review of Economic Studies, 54: 399-412.

P.J. HAMmond (1987b), "On the Impossibility of Perfect Capital Markets," Stanford University Institute of Mathematical Studies in the Social Sciences, Economics Technical Report No. 516.

M. HARRIS AND A. RAVIV (1979), "Optimal Incentive Contracts with Imperfect Information," Journal of Economic Theory, 20: 231-259.

M. Harris And R.M. Townsend (1981), "Resource Allocation under Asymmetric Information," Econometrica, 49: 33-64.

L. Hurwicz, E. Maskin and A. Postlewaite (1979), "Feasible Implementation of Social Choice Correspondences by Nash Equilibrium," Paper presented to the Stanford University Institute of Mathematical Studies in the Social Sciences, Summer Workshop in Mathematical Economics.

D.M. Jaffee AND T. Russell (1976), "Imperfect Information and CreditRationing," Quarterly Journal of Economics, 90: 651-666.

K. JUDD (1985), "The Law of Large Numbers with a Continuum of Random Variables," Journal of Economic Theory, 35: 19-25.

J. M. KEYNES (1936), The General Theory of Employment, Interest and Money. London: Macmillan. 
D. KREPS AND R. WILsON (1982), "Sequential Equilibria," Econometrica, 50: 863-894.

E.S. Maskin (1980), "On First-Best Taxation," in D. Collard, R. Lecomber, M. Slater (ed.), Income Distribution: The Limits to Redistribution (Bristol: John Wright and Sons Ltd.), pp. 9-22.

F. Milne (1980), "Short-Selling, Default Risk and the Existence of Equilibrium in a Securities Model," International Economic Review, 21: 225-267.

J.A. Mirrlees (1971), "An Exploration in the Theory of Optimum Income Taxation," Review of Economic Studies, 38: 175-208.

A. Postlewaite (1979), "Manipulation via Endowments," Review of Economic Studies, 46: 255-262.

A. Postlewaite (1985), "Implementation via Nash Equilibria in Economic Environments," in L. Hurwicz, D. Schmeidler and H. Sonnenschein (ed.), Social Goals and Social Organization: Essays in Memory of Elisha Pazner (Cambridge: Cambridge University Press), ch. 7, pp. 205-228.

A. Postlewaite and D. Schmeidler (1986), "Implementation in Differential Information Economies," Journal of Economic Theory, 39: 14-33.

A. Postlewaite and D. Schmeidler (1987), "Differential Information and Strategic Behavior in Economic Environments: A General Equilibrium Approach," in T. Groves, R. Radner and S. Reiter (ed.), Information, Incentives, and Economic Mechanisms: Essays in Honor of Leonid Hurwicz (Minneapolis: University of Minnesota Press), ch. 12, pp. 330-348.

E.C. Prescott and R.M. Townsend (1984a), "Pareto Optima and Competitive Equilibria with Adverse Selection and Moral Hazard," Econometrica, 52: 21-45 
E.C. Prescott And R.M. Townsend (1984b), "General Competitive Analysis in an Economy with Private Information," International Economic Review, 25: $1-20$.

M. ShubIK (1973), "Commodity Money, Oligopoly, Credit and Bankruptcy in a General Equilibrium Model," Western Economic Journal, 11: 24-38.

M. ShubiK (1974), “Money, Trust and Equilibrium Points in Games in Extensive Form," Zeitschrift für Nationalökonomie, 34: 365-385.

M. ShubiK And C. WiLson (1977), "The Optimal Bankruptcy Rule in a Trading Economy Using Fiat Money," Zeitschrift für Nationalökonomie, 37: 337-354.

G. Stigler (1967), "Imperfections in the Capital Market," Journal of Political Economy, 85: 287-292.

J.E. Stiglitz AND A. Weiss (1981), "Credit Rationing in Markets with Imperfect Information," American Economic Review, 71: 393-410.

J.E. STiglitz AND A. WeIss (1983), "Incentive Effects of Terminations: Applications to the Credit and Labor Markets," American Economic Review, 73: $912-927$.

R.M. Townsend (1979), "Optimal Contracts and Competitive Markets with Costly State Verification," Journal of Economic Theory, 21: 265-293.

R.M. TOWNSEND (1988), "Information Constrained Insurance: The Revelation Principle Extended," Journal of Monetary Economics, 21: 411-450. 


\section{Working Papers of the Department of Economics Published since 1989}

$89 / 370$

B. BENSAID/R.J. GARY-BOBO/

S. FEDERBUSCH

The Strategic Aspects of Profit Sharing in the Industry

$89 / 372$

Jean-Philippe ROBE

Countervailing Duties, State Protectionism and the Challenge of the Uruguay Round

$89 / 374$

Francisco S. TORRES

Small Countries and Exogenous Policy Shocks

\section{$89 / 375$}

Renzo DAVIDDI

Rouble Convertibility: A Realistic Target

\section{$89 / 377$}

Elettra AGLIARDI

On the Robustness of Contestability Theory

\section{$89 / 378$}

Stephen MARTIN

The Welfare Consequences of Transaction Costs in Financial Markets

\section{$89 / 381$}

Susan SENIOR NELLO

Recent Developments in Relations Between the $\mathrm{EC}$ and Eastern Europe

\section{$89 / 382$}

Jean GABSZEWICZ/ Paolo GARELLA/

Charles NOLLET

Spatial Price Competition With Uninformed Buyers

\section{$89 / 383$}

Benedetto GUI

Beneficiary and Dominant Roles in Organizations: The Case of Nonprofits

\section{$89 / 384$}

Agustín MARAVALL/ Daniel PEÑA

Missing Observations, Additive Outliers and Inverse Autocorrelation Function

\section{$89 / 385$}

Stephen MARTIN

Product Differentiation and Market Performance in Oligopoly

\section{$89 / 386$}

Dalia MARIN

Is the Export-Led Growth Hypothesis Valid for Industrialized Countries?

\section{$89 / 387$}

Stephen MARTIN

Modeling Oligopolistic Interaction

\section{$89 / 388$}

Jean-Claude CHOURAQUI

The Conduct of Monetary Policy: What have we Learned From Recent Experience

\section{$89 / 390$}

Corrado BENASSI

Imperfect Information and Financial Markets: A General Equilibrium Model

\section{$89 / 394$}

Serge-Christophe KOLM

Adequacy, Equity and Fundamental Dominance: Unanimous and Comparable Allocations in Rational Social Choice, with Applications to Marriage and Wages

\section{$89 / 395$}

Daniel HEYMANN/ Axel LEIJONHUFVUD

On the Use of Currency Reform in Inflation Stabilization

\section{$89 / 400$}

Robert J. GARY-BOBO

On the Existence of Equilibrium Configurations in a Class of Asymmetric Market Entry Games

\section{$89 / 402$}

Stephen MARTIN

Direct Foreign Investment in The United States

$89 / 413$

Francisco S. TORRES

Portugal, the EMS and 1992: Stabilization and Liberalization

$89 / 416$

Joerg MAYER

Reserve Switches and Exchange-Rate Variability: The Presumed Inherent Instability of the Mulliple Reserve-Currency System

\section{$89 / 417$}

José P. ESPERANÇA/Neil KAY

Foreign Direct Investment and Competition in the Advertising Sector: The Italian Case 
$89 / 418$

Luigi BRIGHI/ Mario FORNI

Aggregation Across Agents in Demand Systems

$89 / 420$

Corrado BENASSI

A Competitive Model of Credit Intermediation

$89 / 422$

Marcus MILLER/ Mark SALMON

When does Coordination pay?

$89 / 423$

Marcus MILLER/ Mark SALMON/

Alan SUTHERLAND

Time Consistency, Discounting and the Returns to Cooperation

$89 / 424$

Frank CRITCHLEY/ Paul MARRIOTT/

Mark SALMON

On the Differential Geometry of the Wald Test with Nonlinear Restrictions

$89 / 425$

Peter J. HAMMOND

On the Impossibility of Perfect Capital Markets

$89 / 426$

Peter J. HAMMOND

Perfected Option Markets in Economies with Adverse Selection

$89 / 427$

Peter J. HAMMOND

Irreducibility, Resource Relatedness, and Survival with Individual Non-Convexities 


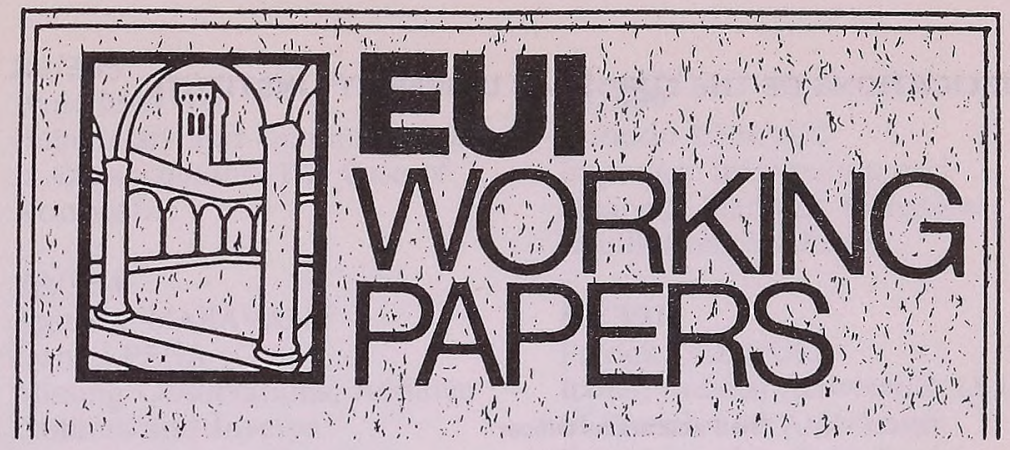

EUI Working Papers are published and distributed by the European University Institute, Florence.

Copies can be obtained free of charge - depending on the availability of stocks - from

The Publications Officer

European University Institute

Badia Fiesolana

I - 50016 San Domenico di Fiesole (FI)

Italy

Please use order form overleaf 


\section{PUBLICATIONS OF THE EUROPEAN UNIVERSITY INSTITUTE}

To

The Publications Officer

European University Institute

Badia Fiesolana

I - 50016 San Domenico di Fiesole (FI)

Italy

From Name

Address

Please send me the following EUI Working Paper(s):

No.

Author, title:

Date 


\section{$89 / 383$}

Benedetto GUI

Beneficiary and Dominant Roles in Organizations: The Case of Nonprofits

\section{9/384}

Agustín MARAVALL/

Daniel PEÑA

Missing Observations, Additive

Outliers and Inverse

Autocorrelation Function

$89 / 385$

Stephen MARTIN

Product Differentiation and

Market Performance in

Oligopoly

\section{$89 / 386$}

Dalia MARIN

Is the Export-Led Growth

Hypothesis Valid for

Industrialized Countries?

$89 / 387$

Stephen MARTIN

Modeling Oligopolistic

Interaction

\section{$89 / 388$}

Iean-Claude CHOURAQUI

The Conduct of Monetary

Policy: What have we Learned

From Recent Experience

\section{$89 / 389$}

Léonce BEKEMANS

Economics in Culture vs.

Culture in Economics
$89 / 390$

Corrado BENASSI

Imperfect Information and

Financial Markets: A General

Equilibrium Model

\section{$89 / 391$}

Patrick DEL DUCA

Italian Judicial Activism in Light

of French and American

Doctrines of Judicial Review and Administrative

Decisionmaking: The Case of Air Pollution

\section{$89 / 392$}

Dieter ZIEGIER

The Bank of England in the Provisus: The Case of the Ieicester Branch Closing, 1872

\section{$89 / 393$}

Gunther TEUBNER

How the Law Thinks:

Toward a Constructivist

Epistemology of Law

\section{$89 / 394$}

Serge-Christophe KOLM

Adequacy, Equity and

Fundamental Dominance:

Unanimous and Coniparable

Allocations in Rational Social

Choice, with Applications to

Marriage and Wages

\section{$89 / 395$}

Daniel HEYMANN/

Axel LEIJONHUFVUD

On the Use of Currency Reform in Inflation Stabilization 
$89 / 396$

Gisela BOCK

Challenging Dichotomies:

Theoretical and Historical

Perspectives on Women's

Studies in the Humanities and

Social Sciences

$89 / 397$

Giovanna C. CIFOLETTI

Quaestio sive aequatio:

la nozione di problema nelle

Regulae

\section{$89 / 398$}

Michela NACCI

L'équilibre difficile. Georges

Friedmann avant

la sociologie du travail

89/399

Bruno WANROOIJ

Zefthe Akaira, o delle identità smarrite

\section{$89 / 400$}

Robert J. GARY-BOBO

On the Existence of Equilibrium Configurations in a Class of

Asymmetric Market Entry

Games

$89 / 401$

Federico ROMERO

The US and Western Europe:

A Comparative Discussion of

Labor Movements in the

Postwar Economy

\section{$89 / 402$}

Stephen MARTIN

Direct Foreign Investment in

The United States
89/403

Christine LAMARRE

La vie des enfants et des vieillards assistés à Dijon au $18^{\mathrm{e}}$ siècle

\section{9/404}

Christian JOERGES

Product liability and product safety in

the European Community

\section{$89 / 405$}

Giandomenico MAJONE

Regulating Europe:

Problems and Prospects

\section{9/406}

Fabio SDOGATI

Exchange Rate Fluctuations and the Patterns of International Trade: A Study of the Flow of Trade from Newly

Industrialized Countries to the European Community at the Industry Level

89/407

Angela LIBERATORE

EC Environmental Research and

EC Environmental Policy:

A study in the utilization of knowledge for regulatory purposes

\section{$89 / 408$}

J. -Matthias Graf von der

SCHULENBURG

Regulation and Deregulation of Insurance Markets in the Federal Republic of Germany 
$89 / 409$

Greg KASER

Acceptable Nuclear Risk: Some

Examples from Europe

$89 / 410$

Léonce BEKEMANS/ Manfred GLAGOW/ Jeremy MOON

Beyond Market and State

Alternative Approaches to

Meeting Societal Demands

\section{$89 / 411$}

Erich KAUFER

The Regulation of Drug

Development: In Search of a

Common European Approach

\section{$89 / 412$}

Gianna GIANNELLI/ Gøsta

ESPING-ANDERSEN

Labor Costs and Employment in the Service Economy

\section{$89 / 413$}

Francisco S. TORRES

Portugal, the EMS and 1992:

Stabilization and Liberalization

\section{$89 / 414$}

Gøsta ESPING-ANDERSEN/

Harald SONNBERGER

The Demographics of Age in

Labor Market Management

\section{$89 / 415$}

Fritz von NORDHEIM NIELSEN

The Scandinavian Model:

Reformist Road to Socialism or

Dead End Street?

\section{$89 / 416$}

Joerg MAYER

Reserve Switches and

Exchange-Rate Variability:

The Presumed Inherent

Instability of the Multiple

Reserve-Currency System

\section{9/417}

José P. ESPERANÇAV Neil KAY Foreign Direct Investment and Competition in the Advertising Sector: The Italian Case

\section{$89 / 418$}

Luigi BRIGHI/ Mario FORNI Aggregation Across Agents in Demand Systems

\section{$89 / 419$}

Hans Ulrich JESSURUN

d'OLIVEIRA

Nationality and Apartheid:

Some Reflections on the Use of Nationality Law as a Weapon against Violation of

Fundamental Rights

\section{$89 / 420$}

Corrado BENASSI

A Competitive Model of Credit Intermediation

\section{$89 / 421$}

\section{Ester STEVERS}

Telecommunications Regulation in the European Community:

The Commission of the

European Communities as

Regulatory Actor

\section{$89 / 422$}

Marcus MILLER/ Mark

SALMON

When does Coordination pay? 
$89 / 423$

Marcus MILLER/ Mark

SALMON/

Alan SUTHERLAND

Time Consistency, Discounting

and the Returns to Cooperation

$89 / 424$

Frank CRITCHLEY/ Paul

MARRIOTT/

Mark SALMON

On the Differential Geometry of

the Wald Test with Nonlinear

Restrictions

$89 / 425$

Peter J. HAMMOND

On the Impossibility of Perfect

Capital Markets

$89 / 426$

Peter J. HAMMOND

Perfected Option Markets in

Economies with Adverse

Selection

\section{$89 / 427$}

Peter J. HAMMOND

Irreducibility, Resource

Relatedness, and Survival with

Individual Non-Convexities

\section{$89 / 428$}

Joanna GOYDER

"Business Format" Franchising and EEC Competition Law 